\title{
Evaluation of ERP Systems Quality Model Using Analytic Hierarchy Process (AHP) Technique
}

\author{
Thamer A. Al-Rawashdeh1, Feras M. Al'azzeh², Sokyna M. Al-Qatawneh³ \\ ${ }^{1}$ Department of Computer Science, Alzaytoonah University of Jordan, Amman, Jordan \\ ${ }^{2}$ Department of Basics Science, Alzaytoonah University of Jordan, Amman, Jordan \\ ${ }^{3}$ Department of Mutimedia, Alzaytoonah University of Jordan, Amman, Jordan \\ Email: Thamer.R@zuj.edu.jo, drferas@zuj.edu.jo, S.Qatawneh@zuj.edu.jo
}

Received 24 January 2014; revised 20 February 2014; accepted 27 March 2014

Copyright (C) 2014 by authors and Scientific Research Publishing Inc.

This work is licensed under the Creative Commons Attribution International License (CC BY). http://creativecommons.org/licenses/by/4.0/

\section{(c) (i) Open Access}

\section{Abstract}

The Enterprise Resource Planning (ERP) system is a complex and comprehensive software that integrates various enterprise's functions and resources. ERP system cleanly encapsulates crosscutting concerns which cannot be encapsulated by other types of information systems like data synchronization and standardization, system complexity and system modularity. Many studies are conducted to propose software quality models with their quality characteristics. However, there is currently no dedicated software quality model that can describe and involve new features of ERP systems. Thus, this study has proposed an ERP system quality model (ERPSQM). Analytic Hierarchy Process AHP has been employed to evaluate the quality of ERPSQM. Furthermore, this proposed model can be used to make a comparison of ERP systems to help companies implement better systems.

\section{Keywords}

ERP Systems, ERP Systems Quality, Quality Characteristics of ERP Systems, Analytic Hierarchy Process (AHP)

\section{Introduction}

The Enterprise Resource Planning (ERP) system is a complex and comprehensive software developed to better integrate firms' functions and resources [1]. Today, most organizations use the ERP systems due to cost reductions, improving responsiveness to customer needs, replacement of legacy systems, and faster data transactions 
[1]-[3]. However, many studies have shown a rather high failure rate in the implementation of ERP systems [3]-[5]. Many features must be considered for high quality systems with the focus on ERP system characteristics, in which assuring successfully developing and implementing the systems.

With respect to the software systems quality, much work has been conducted to propose software quality models and metrics. Among these models are McCall's software quality model, Boehm's software product quality model, Dromey's quality model, FURPS quality model and ISOVIEC 9126. The metrics are qualitative indicators of system characteristics and the quality models explain the relationships between such metrics [6]. Additionally, other studies have been conducted to provide guidelines for evaluating the quality of different types of software systems. However, there is a lack of studies conducted to propose ERP systems quality models and their characteristics [5].

The ERP systems have different type of abstraction. In additional to its complexity and modularity, the basic concept in the ERP system is the standardization and synchronization of information [3]. Thus, most of software quality characteristics and sub-characteristics of ISO/IEC 9126 will be applicable to the ERP system quality model with appropriate modification. Because of the new abstraction type in ERP system, some new software quality characteristics should be involved, which can describe new features of ERP system. So, the novelty of this work is to derive the ERP Software Quality Model (ERPSQM) from ISO/IEC 9126 in which compatibility, Modularity, complexity, and reusability have been involved as sub-characteristics under characteristics functionality, usability and maintainability.

Consequently, the Analytic Hierarchy Process (AHP) technique has been applied for evaluating the quality and ranking the characteristics of the ERP system quality model. AHP has extensively been applied in multi-criteria decision making and to many practical decision making problems [7].

\section{Literature Review}

In order to propose an appropriate software quality model for ERP systems, this section highlights the most popular software quality models in the literature, their contributions and disadvantages. These models are McCall's software quality model, Boehm's software product quality model, Dromey's quality model, FURPS quality model and ISOIIEC 9126.

\subsection{McCall's Quality Model}

McCall's model is one of the most commonly used software quality models (Panovski, 2008). This model provides a framework to assess the software quality through three levels. The highest level consists eleven quality factors that represent the external view of the software (customers' view), while the middle level provides twenty three quality criteria for the quality factors. Such criteria represent the internal view of the software (developers' view). Finally, on the lowest level, a set of matrices is provided to measure the quality criteria [8]. The contribution of the McCall Model is assessing the relationships between external quality factors and product quality criteria [9]. However, the disadvantages of this model are the functionality of a software product is not present and not all matrices are objectives, many of them are subjective [10].

\subsection{Boehm's Quality Model}

In order to evaluate the quality of software products, Boehm proposed quality model based on the McCall's model. The proposed model has presented hierarchical structure similar to the McCall's model [11]. Many advantages are provided by the Boehm's model, namely taking the utility of a system into account and extending the McCall model by adding characteristics to explain the maintainability factor of software products [9]. However, it does not present an approach to assess its quality characteristics [12].

\subsection{FURPS Quality Model}

The FURPS model was introduced by Robert Grady in 1992 [13]. It's worth mentioning that, the name of this model comes from five quality characteristics, including Functionality, Usability, Reliability, Performance and Supportability. These quality characteristics have been decomposed into two categories: functional and nonfunctional requirements [13]. The functional requirements defined by inputs and expected outputs (functionality), while nonfunctional requirement composes reliability, performance, usability and supportability. However, the one disadvantage of this model is the software portability has not been considered [14]. 


\subsection{Dromey's Quality Model}

Dromey’s model extended the ISO 9126: 1991 by adding two high-level quality characteristics to introduce a framework for evaluating the quality of software products. Therefore, this model comprehends eight high-level characteristics. Such characteristics are organized into three quality models including requirement quality model, design quality model and implementation quality model [15]. According to Behkamal et al. [10], the main idea behind Dromey's model reveals that, formulating a quality model that is broad enough for different systems and assessing the relationships between characteristics and sub-characteristics of software product quality.

The One disadvantage of Dromey's model is the reliability and maintainability characteristics could not be judged before a product actually implemented [9].

\subsection{ISO 9126 Model}

ISO 9126 is an international standard for software quality evaluation. It was originally presented in 1991; then it had been extended in 2004. The ISO 9126 quality model presents three aspects of software quality which address the internal quality, external quality and quality in use [16]. Therefore, this model evaluates the quality of software in term the external and internal software quality and their connection to quality attributes. In this respect, the model presents such quality attributes as a hierarchical structure of characteristics and sub-characteristics. The highest level composes six characteristics that are further divided into twenty one sub-characteristics of the lowest level. The main advantage of this model is the model could be applied to the quality of any software product [9].

Because of the ISO/IEC 9126 provides quality characteristics and sub-characteristics that are general and common for evaluating the quality of every type of software products, the recently proposed quality models have been derived from ISO/IEC 9126. For example, Kumar et al. [6] have proposed quality model depend on ISO/IEC 9126 in order to evaluate the quality of aspect-oriented software. Adnan et al. [17] have also proposed model to evaluate the quality of COST systems. Additionally, Bertoa et al. [18] have adapted the ISO/IEC 9126 to establish a component-based systems quality model. Therefore, the ISO/IEC 9126 is adapted in this work to propose the ERP software quality model.

\section{ERPSQM}

In order to define a software quality model which should comprise all the features of ERP systems, the new features of ERP systems should be recognized. The ERP system is complex and comprehensive software used to integrate organization functions and resources. As well as, the main concentration of ERP systems is providing real-time and accurate information. Other features of an ERP system that should be considered, are system modularity and modules reusability. It indicates that the ERP system quality model can be extended from any standard quality model which is applicable to the ERP system nature. Other quality characteristics and sub-characteristics are required to be involved, which can cover the new features of ERP systems, including the system complexity, information synchronization and standardization, modularity of systems and modules reusability. Redefined existing quality characteristics and sub-characteristics are also required in context of ERP systems.

ISO/IEC 9126 has been extended to propose the ERPSQM. The compatibility and modularity has been added as sub-characteristics under functionality, complexity as sub-characteristics under usability, and reusability under maintainability. Definition and justification of new and existing ISO/IEC 9126 characteristics and sub-characteristics are given in the next section.

\subsection{Definitions of New Sub-Characteristics Added To ERPSQM}

\subsubsection{Compatibility}

The compatibility was defined as "the degree to which an innovation is perceived as being consistent with the existing values, needs and past experience of potential adopter” [19]. In this work, an ERP system is a suite of software models and each module has its own functions. In all probability, in order to perform a particular function, exchange data between the modules or with other stand alone applications that mostly used with an ERP system, is required. In other words, the compatibility refers to the capability of ERP system modules to exchange data between each other and with other applications [3]. Therefore, the compatibility is added as a sub-characteristic under functionality characteristic. 


\subsubsection{Complexity}

As previously mentioned, the ERP system is integrated suite software modules that support firms' functions and resources. The complexity of such system is due the interaction between its software modules [6] [17]. So, the complexity characteristic could be useful not only in efforts that are needed for development and maintenance a system, but also efforts needed to move from module to another by the end user. The Less complex system will be easier for developing and using [3]. That's why the complexity proposed as a sub-characteristic under usability characteristics.

\subsubsection{Modularity}

One of the most obstacles to implement ERP systems is the development cost, especially in small firms [20]. However, an ERP system is a set of software modules, each module permits automating a certain function. All software modules could be installed and implemented as single, so companies can implement only the modules that are required for its functions and compatible with their resources, in which they can reduce the development costs [3]. For this reason, the modularity has been added to the ERPSQM as a sub-characteristic under functionality characteristic.

\subsubsection{Reusability}

The reusability is defined as "use of software originally developed for one project to a new software project currently being developed" [17]. The reuse of software is expected to shorten the development period of time; to save development resources; and to provide tested and validated modules (high quality modules).So, due to reducing the implement cost companies could share some ERP system modules [17]. Sometimes organizations need to customize the modules according to their functions and process (by a third party provider or in-house). Such customization includes adding new functions and adjusting existing functions [3]. Thus, one of the most important ERP system features is the reusability. For this reason, reusability has been proposed to be involved in ERPSQM as sub-characteristic under maintainability characteristic.

\subsection{Definitions of Existing Characteristics in ERP Systems Context}

The quality characteristics, functionality, reliability, usability, efficiency, maintainability, and portability have commonly been proposed in most quality models. However, scholars have different opinions while choosing subcharacteristics of these characteristics. This research concentration is on the product quality rather than on quality in use. Therefore, this section defines the various characteristics and its sub-characteristics in term of ERP systems.

The Functionality has been defined by ISO [21] as the capability of the software to provide functions which meet the stated and implied needs of users under specified conditions of usage. In order to evaluate such characteristic, it has been divided into four sub-characteristics, namely accuracy, suitability, interoperability, and security [6]. Adapting the functionality of the ERP systems reveals that the systems software should provide its functions, namely financial process, human resource management, supply chain process, manufacturing process and/ or customer service process as per the requirements when it is used under specific conditions. Therefore, as previously mentioned additional two sub-characteristics have significantly been proposed under this quality characteristic including modularity and compatibility.

The reliability is the capability of the software to maintain its level of performance under stated conditions for a stated period of time. Reliability has three sub-characteristics consist maturity, fault tolerance, and recoverability [9]. In terms of ERP systems, the reliability refers to the capability of the systems to maintain its service provision under specific conditions for a specific period of time. In other words, the probability of the ERP system fails in a problem within a given period of time.

The usability is the capability of the software to be understood learned, used, and attractive by the users, when used under specified conditions. The usability has set of sub-characteristics, including understandability, learn ability, and operability [22]. This characteristic is employed in this study to suggest that the ERP systems should be understood, learned, used and executed under specific conditions. Thus, the complexity has been proposed as additional sub-characteristic under this quality characteristic.

The efficiency refers to the capability of a system to provide performance relative to the amount of the used resources, under stated conditions. To be measured, it has also been divided into three sub-characteristics, namely 
time behaviour, resource utilization an efficiency compliance [21]. Adapting this characteristic to the ERP systems suggests that the systems should be concerned with the used software and hardware resources when providing the ERP systems' functions.

The maintainability is the capability of the software to be modified. The maintainability consists five sub-characteristics, including analyzability, changeability, stability, and testability [14] [16]. In this research, any feature or part of the ERP system should be modifiable. As well as identifying a feature or part to be modified, modifying, diagnosing causes of failures, and validating the modified ERP system should not require much effort. Thus, reusability has been proposed as sub-characteristics under this quality characteristic.

Finally, the portability of software refers to the capability of the software to be transferred from one environment to one another [21]. Therefore, the ERP system should be applied using different operating systems; be applied at different organizations or departments; and be applied using a variety of hardware. Similar to the previous quality characteristics, the portability has set of sub-characteristics, namely adaptability, installability, coexistence, and replace ability [9].

Table 1 mentions the ERPSQM, its quality characteristics, and sub-characteristics. As well as, how these quality characteristics and sub-characteristics influence the quality of ERP systems in organizations.

\section{Table 1. ERP Systems Quality Model (ERPSQM).}

\begin{tabular}{|c|c|c|}
\hline Characteristic & Sub-characteristic & Description \\
\hline \multirow{4}{*}{ Functionality } & Suitability & Can the ERP software perform the required functions? \\
\hline & Accurateness & Are the results of ERP software as anticipated? \\
\hline & Interoperability & Can the ERP software interact with other systems \\
\hline & $\begin{array}{c}\text { Security } \\
\text { Compatibility } \\
\text { Modularity }\end{array}$ & $\begin{array}{l}\text { Can the ERP software prevent unauthorized access? } \\
\text { Can the ERP software exchange information between its } \\
\text { modules and with other stand-alone applications. } \\
\text { Could be ERP software modules Installed and implemented as single? }\end{array}$ \\
\hline \multirow{4}{*}{ Reliability } & Maturity & Have faults in the ERP software and hardware devices been eliminated over time? \\
\hline & Fault tolerance & $\begin{array}{l}\text { Is the ERP software capable to maintain a specified level of } \\
\text { performance in case of software and hardware errors? }\end{array}$ \\
\hline & Recoverability & Can the ERP software resume working and recover affected data in case of a failure? \\
\hline & Understandability & Does the ERP software's user recognize how to use the software easily? \\
\hline \multirow{3}{*}{ Usability } & Learnability & Can the ERP software be learnt easily? \\
\hline & Operability & Can the ERP software work with a minimal effort? \\
\hline & Complexity & Can the ERP software's user interact with variety of the software modules easily? \\
\hline \multirow{4}{*}{ Efficiency } & Time behaviour & How quickly does the ERP software respond? \\
\hline & Resource utilization & Does the ERP software utilize resources efficiently? \\
\hline & Efficiency compliance & Does the ERP software adhere to the existing efficiently standards? \\
\hline & Analyzability & $\begin{array}{c}\text { Does diagnose fault or identification a module to be modified within } \\
\text { the ERP software, require a minimal effort? }\end{array}$ \\
\hline \multirow{3}{*}{ Maintainability } & Changeability & Can ERP software modules be modified easily? \\
\hline & Stability & Can ERP software modules continue functioning after the change? \\
\hline & $\begin{array}{l}\text { Testability } \\
\text { Reusability }\end{array}$ & $\begin{array}{l}\text { Can a modified ERP software module be easily validated? } \\
\text { Could ERP software modules to be used in a new project being currently developed? }\end{array}$ \\
\hline \multirow[t]{3}{*}{ Portability } & Adaptability & Can ERP software modules be moved easily to the other environment? \\
\hline & Installability & Can ERP software software modules be installed easily? \\
\hline & Replaceability & Can the ERP software be replaced easily with similar system? \\
\hline
\end{tabular}




\section{Evaluation of ERPSQM Using Analytic Hierarchy Process (AHP)}

This study not only proposes a quality model for the ERP systems, but also applies Analytic hierarchy Process (AHP) to rank and evaluate the quality of characteristics and sub-characteristics of such model. Analytic hierarchy Process (AHP) could be applied to measure quality as a single parameter. The AHP is a multi-criteria decision making method that was proposed by Thomas L. Saaty in 1980 [7]. Interestingly, in order to evaluate ambiguity in multi-criteria decision making problems, the AHP uses the pair-wise matrix [6]. Human judgment is not always consistent. Therefore, the AHP allows some small consistency in the matrix. In the case of consistency, find vector $\omega$ satisfying Equation (1).

$$
A \cdot \omega=\lambda \max \omega \text {, and } \lambda \max >n \text {. }
$$

where $\omega$ is eigenvectors; $\lambda$ is eigenvalues; and $n$ represents the number of elements to be compared. The difference between $\lambda$ and $n$ is an indication of judgment consistency.

In order to verify the consistency of comparison matrix, Saaty [7] proposed a Consistency Index (CI) and Consistency Ratio (CR), Equations (2) and (3).

$$
\begin{aligned}
& \mathrm{CI}=\frac{\lambda \max -n}{n-1} \\
& \mathrm{CR}=\frac{\mathrm{CI}}{\mathrm{RI}}
\end{aligned}
$$

where CR is the average of consistency index and should satisfy the condition of CR less than or equal 0.1.

\subsection{Allocating the Weights of ERPSQM Characteristics and Sub-Characteristics}

In this study, survey on twenty experts has been conducted, in order to assign pair wise relative weights to ERPSQM characteristics and sub-characteristics. Out of these experts, eight professionals are working at software industry and experts of ERP systems development. Remaining twelve are academicians who have whether good knowledge of the ERP systems or are doing their research in such area. Only fifteen of the experts had filled the survey forms and successfully sent it back. The survey form involves seven tables for filling the pair wise relative weight values of ERSQM characteristics and sub-characteristics. First table is for filling the pair wise relative weight values of the model characteristics, namely functionality, reliability, usability, efficiency, maintainability and portability. The remaining tables are for filling the pair wise relative weight values of sub-characteristics of the ERSQM's characteristics. The means of collected data on pair wise weight values of characteristics and sub-characteristics are filled in the square matrices, to apply the PHP process and then calculate the Eigenvectors $(\omega)$ and Eigenvalues (ג). For instance, A [aij], in Equation (4) represents the square matrix of six main the ERSQM's characteristics.

$$
\mathrm{A}[\mathrm{aij}]=\left[\begin{array}{ccccccc} 
& F & R & U & M & E & P \\
F & 1 & 2.534 & 2.735 & 5.933 & 3.524 & 5.800 \\
R & 0.395 & 1 & 2.597 & 3.622 & 2.731 & 5.133 \\
U & 0.366 & 0.385 & 1 & 3.579 & 2.325 & 4.156 \\
M & 0.169 & 0.276 & 0.279 & 1 & 0.341 & 3.690 \\
E & 0.284 & 0.366 & 0.430 & 2.930 & 1 & 4.067 \\
P & 0.172 & 0.195 & 0.241 & 0.271 & 0.246 & 1
\end{array}\right]
$$

\subsection{Calculating Eigenvector and Eigen-Value}

The next step is to determine the eigenvectors. In this respect, there are many ways to calculate the priority vector, which is the Eigenvector. Multiplying the entries of each row in the matrix and then calculate the $6^{\text {th }}$ roots of a product. The 6th roots are summed and that sum used to normalize the eigenvector values, since the sum of its column is one. Later, the6th root of each column is divided by the sum of the 6th roots column.

Table 2 presents all the calculations. It could be seen that, the eigenvector of relative importance or in the other words the weights of the main characteristics as the following: functionality (0.384), reliability (0.242), usability (0.163), efficiency (0.113), maintainability (0.063), portability (0.036). Therefore, from developers' and acade- 
Table 2. Eigenvector and eigenvalue.

\begin{tabular}{|c|c|c|c|c|c|c|c|c|c|c|}
\hline & $\mathrm{F}$ & $\mathrm{R}$ & $\mathrm{U}$ & M & $\mathrm{E}$ & $\mathrm{P}$ & 6th root & $\omega$ & $A \cdot \omega$ & $\lambda$ \\
\hline $\mathrm{F}$ & 1 & 2.534 & 2.735 & 5.933 & 3.524 & 5.800 & 3.072 & 0.384 & 2.420 & 6.297 \\
\hline $\mathrm{R}$ & 0.395 & 1 & 2.597 & 3.622 & 2.731 & 5.133 & 1.932 & 0.242 & 1.535 & 6.352 \\
\hline $\mathrm{U}$ & 0.366 & 0.385 & 1 & 3.579 & 2.325 & 4.156 & 1.302 & 0.163 & 1.032 & 6.338 \\
\hline M & 0.169 & 0.276 & 0.279 & 1 & 0.341 & 3.690 & 0.504 & 0.063 & 0.410 & 6.506 \\
\hline $\mathrm{E}$ & 0.284 & 0.366 & 0.430 & 2.930 & 1 & 4.067 & 0.900 & 0.113 & 0.710 & 6.304 \\
\hline \multirow[t]{2}{*}{$\mathrm{P}$} & 0.172 & 0.195 & 0.241 & 0.271 & 0.246 & 1 & 0.285 & 0.036 & 0.233 & 6.530 \\
\hline & & & & & & & 7.996 & 1 & & 6.388 \\
\hline
\end{tabular}

micians' perspectives functionality of the ERP systems is the most important one over other characteristics, followed by reliability, usability, efficiency, maintainability, and the portability of the ERP systems is less important. These results provide more than ranking. In fact, the relative weights are a ratio scale could be divided among such quality characteristics.

The next step is to check the consistency of participants' answers by obtaining consistency index (CI) and consistency ratio (CR) from Equations (2) and (3) to do that, the eigenvalueis required. Eigenvalue could be calculated from the Formula (1). All the values which obtained were merged with the values in the Table 2 . These results reveal that $\lambda$ valueshave satisfied the condition of $\lambda>n$, and the mean of $\lambda$ values is $6.388>6$.

By applying Equations (2) and (3), CI $=\frac{\lambda \max -n}{n-1}=\frac{6.388-6}{5}=0.078$, so CR $=0.063$. Therefore, the estimation is acceptable because $\mathrm{CR}<0.1$.

Similarly, AHP process has been applied to calculate eigenvectors and eigenvalue of sub-characteristics of quality characteristics of functionality through portability. the results come as the following: the eigenvector values $(0.382,0.252,0.081,0.119,0.90,0.048$ and 0.029$)$ are for sub-characteristics of functionality, (0.687, 0.226 and 0.087 ) are for sub-characteristics of reliability, $(0.608,0.217,0.086$ and 0.089$)$ for sub-characteristics of usability, $(0.505,0.196,0.140,0.063$ and 0.096$)$ for maintainability sub-characteristics, $(0.536,0.241,0.144$ and 0.078) for efficiency sub-characteristics, and (0.705, 223 and 0.073) for sub-characteristics of portability. Regarding the consistency test, all the estimates are acceptable, since all the CR values of the sub-characteristics are less than 0.1 .

Therefore, this empirical study provides companies and organizations with the quality characteristics and their importance that should be taken into account in developing and implementing the ERP systems. In which it can be assured that the ERP systems will be successfully implemented.

\section{Conclusions}

The aim of this study is to develop a new ERP Systems Quality Model. This model is an extension of ISO/IEC 9126 international software quality standard that has been agreed upon by a majority of the international community. The proposed model enhances the hierarchy of this standard by adding some new sub-characteristics, including compatibility, modularity, complexity, and reusability, which have been added under the characteristics of functionality, usability and maintainability. These new sub-characteristics are involved on the basis of the new features of the ERP systems over other types of the information systems. Existing characteristics and sub-characteristics of ISO/IEC 9126, which are part of ERPSQM, have also been defined in the context of the ERP systems.

In order to evaluate the quality of the proposed model and ranking its characteristics and sub-characteristics, Analytic Hierarchy Process (AHP) has been applied. Pair wise relative weights of characteristics and sub-characteristics have been taken through a survey on twenty experts. The mean of collecting data is considered as pair wise relative weights. Consequently, AHP is applied to such pair wise relative weights to get the corresponding relative weights of proposed model's characteristics and sub-characteristics, in which the total quality weights equal one. 


\section{References}

[1] Ifinedo, P. and Nahar, N. (2006) Quality, Impact and Success of ERP Systems: A Study Involving Some Firms in the Nordic-Baltic Region. Journal of Information Technology Impact, 6, 19-46.

[2] Tatari, O., Castro-Lacouture, D. and Skibniewski, M.J. (2007) Current State of Construction Enterprise Information Systems: Survey Research. Construction Innovation, 74, 310-319. http://dx.doi.org/10.1108/14714170710780075

[3] Chung, B., Skibniewski, M.J., Lucas, Jr., H.C. and Kwak, Y.H. (2008) Analyzing Enterprise Resource Planning System Implementation Success Factors in the Engineering-Construction Industry. Journal of Computing in Civil Engineering, 226, 373-382.

[4] Zornada, L. and Velkavrh, T.B. (2005) Implementing ERP Systems in Higher Education Institutions. Proceedings of 27th International Conference on Information Technology, ICTI, Cavtat, 20-23 June 2005, 7 Pages.

[5] Thamer, A., Mommad, I. and Ahmad, A. (2013) Software Quality Model of ERP System in Higher Education Institutions. European Journal of Scientific Research, 99, 15-21.

[6] Kumar, A., Grover, P.S. and Kumar, R. (2009) A Quantitative Evaluation of Aspect-Oriented Software Quality Model (AOSQUAMO). ACM SIGSOFT Software Engineering Notes, 34, 1-9. http://dx.doi.org/10.1145/1598732.1598736

[7] Saaty, T.L. (1980) The Analytic Hierarchy Process. McGraw, Hill International, New York.

[8] McCall, J.A., Richards, P.K. and Walters, G.F. (1977) Factors in Software Quality. US Rome Air Development Center Reports, US Department of Commerce, Washington DC.

[9] Fahmy, S., Haslinda, N., Roslina, W. and Fariha, Z. (2012) Evaluating the Quality of Software in e-Book Using the ISO 9126 Model. International Journal of Control and Automation, 5, 115-122.

[10] Behkamal, B., Kahani, M. and Akbari, M.K. (2009) Customizing ISO 9126 Quality Model for Evaluation of B2B Applications. Journal Information and Software Technology, 51, 599-609. http://dx.doi.org/10.1016/j.infsof.2008.08.001

[11] Boehm, B.W., Brown, J.R., Kaspar, H., Lipow, M., McLeod, G. and Merritt, M. (1978) Characteristics of Software Quality. North Holland Publishing, Amsterdam.

[12] Panovski, G. (2008) Product Software Quality. Department of Mathematics and Computing Science, Technishe University Eindhoven, Eindhoven.

[13] Grady, R.B. (1992) Practical Software Metrics for Project Management and Process Improvement. Prentice Hall, Englewood Cliffs.

[14] Al-Qutaish, R.E. (2010) Quality Models in Software Engineering Literature: An Analytical and Comparative Study. Journal of American Science, 6, 166-175.

[15] Dromey, R.G. (1996) Concerning The Chimera [Software Quality]. IEEE Software, 13, 33-43. http://dx.doi.org/10.1109/52.476284

[16] ISO (2004) ISO/IEC TR 9126-4: Software Engineer in—Product Quality—Part 4: Quality in Use Metrics. International Organization for Standardization, Geneva.

[17] Adnan, R. and Bassem, M. (2006) A New Software Quality Model for Evaluating COTS Components. Journal of Computer Science, 2, 373-381. http://dx.doi.org/10.3844/jcssp.2006.373.381

[18] Bertoa, M. and Vallecillo, A. (2002) Quality Attributes for COTS Components. The 6th International ECOOP Workshop on Quantitative Approaches in Object-Oriented Software Engineering, Malaga, 11 June 2002, 54-66.

[19] Moore, G.C. and Benbasat, I. (1991) Development of an Instrument to Measure the Perceptions of Adopting an Information Technology Innovation. Information Systems Research INFORMS, 2, 192-222. http://dx.doi.org/10.1287/isre.2.3.192

[20] Ahmad, R.M.T., Othman, Z. and Mukhtar, M. (2011) Campus ERP Implementation Framework for Private Institution of Higher Learning Environment in Malaysia. WSEAS Transactions on Advance in Engineering Education, 8, 1-12.

[21] ISO (2001) ISO/IEC 9126-1: Software Engineering_Product Quality—Part 1: Quality Model. International Organization for Standardization, Geneva.

[22] Kalaimagal, S. and Srinivasan, R. (2008) A Retrospective on Software Component Quality Models. SIGSOFT Software Engineering, 33, 1-10. http://dx.doi.org/10.1145/1449603.1449611 